\title{
A GÊNESE DA POLÍTICA IMPERIALISTA: "A ALIANÇA ENTRE A RALÉ E O CAPITAL” E “O PECADO ORIGINAL DO ACÚMULO ORIGINAL DE CAPITAL” NA PERSPECTIVA DE HANNAH ARENDT
}

Daner Hornich ${ }^{1}$

\section{Resumo:}

O presente artigo pretende analisar o pensamento político, social, histórico e econômico da "evolução dos fenômenos" da "gênese da política Imperialista: "a aliança entre a ralé e o capital" e "o pecado original do acúmulo original de capital" na perspectiva da Hannah Arendt" em diálogo aberto, analítico e reflexivo com os autores modernos e contemporâneos da filosofia, da historiografia, da antropologia, das ciências sociais e da economia, para melhor compreender os significados dos desdobramentos do imperialismo e da "decadência do que sobrou" dos eventos fundamentais dos nossos tempos - as duas grandes guerras mundiais, com a suas perspectivas totalitárias. Sendo assim, o imperialismo e os problemas resultantes das suas propostas sociais, políticas, econômicas produziram "gentes desprovidas de raízes" - a ralé que suplantada pela burguesia que imprimiu o "poder pelo amor ao poder" e da produção ilimitada da "acumulação do capital supérfluo", que fez emergir as formas decantadas em ebulições de questões permeadas pela violência estatal, racial, policial, ambiental, nacional, ilegal e oportunista no cenário do sistema internacional que atravessa os nossos tempos como questões centrais da "nossa condição humana", como as instituições políticas públicas que servem de fachadas para os interesses privados que promoveram e promovem a "chantagem econômica" do "domínio total", da "criminalidade organizada" sem escrúpulo e rotineira contra a população e os cidadãos em suas atividades espontâneas no campo das palavras e das ações.

Palavras-Chave: Imperialismo. Capital. Ralé. Estado. Burguesia

\section{THE GENESIS OF IMPERIALIST POLICY: "THE ALLIANCE BETWEEN MOB AND CAPITAL" AND "THE ORIGINAL SIN OF THE ORIGINAL ACCUMULATION OF CAPITAL" IN HANNAH ARENDT'S PERSPECTIVE}

\begin{abstract}
:
This article analyzes the political, social, historical and economic thought of the "evolution of the phenomena" of the "genesis of imperialist policy: "the alliance between mob and capital" and "the original sin of the original accumulation of capital" in Hannah Arendt's perspective, in open, analytical and reflective dialogue with modern and contemporary philosophy, historiography, anthropology, social sciences and economy writers, in order to deliver a better understanding on the meanings of
\end{abstract}

\footnotetext{
${ }^{1}$ Possui doutorado em filosofia (PUC-SP). Professor do Centro Universitário Salesiano de São Paulo. Participa do Grupo de Pesquisa Filosofia Política Contemporânea da PUC-SP. E-mail: danerhornich@ hotmail.com.
} 
imperialism developments and of the "decay of what is left" based on fundamental events of our time - the two world wars, along with their totalitarian outlooks. Thus, imperialism and the problems arising from its social, political and economic proposal produced "people without roots" - the rabble supplanted by the bourgeoisie who printed "the power by the love of power" and the unlimited production of "needless capital accumulation", who made emerge the decanted manners through boiling issues permeated by state-owned, racial, constabulary, environmental, national, illegal and opportunistic violence in the international scenario crossing our times as central issues of "our human condition", such as the public institutions working for private interests only who have promoted and still promote "economic blackmail" of "total control", of "organized criminality" routinely and without scruples against the people and the citizens in their spontaneous activities in the field of words and actions.

Key Words: Imperialism. Capital. Rabble. State. Bourgeoisie.

\section{Introdução:}

A pesquisa sobre A gênese da política Imperialista: “a aliança entre a ralé e o capital" e "o pecado original do acúmulo original de capital" na perspectiva da Hannah Arendt é uma leitura do fenômeno imperialista de 1884 - 1914 de século XIX, com a pretensão de verificar os seus impactos nos eventos contemporâneos dos sistemas mundiais ${ }^{2}$.

\section{A gênese da política Imperialista: "a aliança entre a ralé e o capital" e "o pecado original do acúmulo original de capital” na perspectiva da Hannah Arendt}

\footnotetext{
2 "Foi a política imperialista, mais que qualquer outro fator, que provocou o declínio da Europa, e parecem ter-se realizado s previsões dos estadistas e historiadores de que os dois gigantes localizados nos flancos leste e oeste das nações europeias emergiram finalmente como herdeiros do poder europeu. Hoje ninguém mais procura justificar a expansão com a afirmações da 'consciência tribal ampliada' que pretendia unir os povos de origem étnica semelhantes; em vez disso, fala-se de 'compromissos' com os movimentos revolucionários 'de libertação nacional'. A palavra 'expansão' desapareceu do vocabulário político, que agora emprega termos como 'extensão' ou 'união', o que diz quase a mesma coisa. Mais importantes politicamente, os investimentos privados em terras distantes, originariamente constituíam a motivação básica do imperialismo, estão hoje superados pela ajuda externa, econômica e militar, fornecida diretamente aos governos pelos governos. (apenas em 1966, o governo americano despendeu 4,6 bilhões de dólares em ajuda econômica e créditos para o exterior, mais 1,3 bilhões por ano em ajuda militar na década de 1956-1965, enquanto o fluxo de capital privado foi de 3,69 bilhões de dólares em 1965 e de 3,91 em 1966). Isso significa que a era do imperialismo do dólar, que foi a versão especificamente norte-americana, e politicamente menos perigosa, do imperialismo anterior à Segunda Guerra Mundial, terminou definitivamente. Os investimentos privados - 'as atividades de quase mil companhias norte-americanas eu operam numa centenas de países estrangeiros, concentradas nos setores mais modernas, mais estratégicos e de mais rápido crescimento da economia estrangeira' - criam muitos problemas políticos, mesmo que não sejam protegidos pelo poder da nação que os origina, mas o auxílio externo, mesmo que seja fornecido por motivos puramente humanitários, é político por natureza, uma vez que se desconhece a motivação do lucro (...). Em outras palavras, a motivação do lucro, cuja importância para a política imperialista foi frequentemente exagerada, mesmo no passado, agora despareceu, e somente os países muito ricos e muitos poderosos podem suportar as enormes perdas que o imperialismo acarreta." (ARENDT, 1989, 150).
}

\begin{tabular}{|l|l|l|l|l|}
\hline Q Povista Qialectus & Ano 4 & n. 10 & Janeiro-Julho 2017 & p. 248-264 \\
\hline
\end{tabular}


A gênese da política imperialista remonta a "emancipação da burguesia" como evento principal do período imperialista, pois na leitura da Hannah Arendt a burguesia foi a "primeira classe na história a ganhar proeminência econômica sem aspirar o domínio político", mas tal posicionamento só foi possível até o momento em que o Estado-nação enquanto estrutura de organização política não foi capaz de gerenciar o seu crescimento econômico capitalista (Cf. ARENDT, 1989, 153 - 154). Seguindo o argumento da autora a burguesia se desenvolveu em conjunto com o "Estado-nação". Contudo, se colocou "acima e além" das "sociedades divididas em classes" e se posicionou numa guerra aberta e constante contra o Estado para afirmar o seu poder (idem, p. 154) . $^{3}$.

Essa atitude de usar os instrumentos de violência do Estado $^{4}$ para o seu crescimento econômico e lutar contra o Estado em determinados momentos do período imperialista não garantiu a vitória da burguesia sobre o Estado, mas tomou outro rumo na história quando a burguesia alemã em declínio "arrancou as máscaras da hipocrisia" (Idem, p. 186) $)^{5}$, confessou o "seu parentesco com a escória” e o submundo (Idem, p, 186) para defender suas propriedades e aceitou as mudanças dos "padrões morais" e, sociais do "realismo" (idem, p. 185 - 186) político proposto por Hobbes de "acúmulo de poder"6 (Idem, p.168). Como expressou Hobbes ao argumentar sobre a "condição miserável da humanidade relativa à sua felicidade e miséria":

\footnotetext{
3“A concepção burguesa de Estado surge na luta contra a política mercantilista, na luta contra o poder centralizado e privilegiado do poder estatal. Ela defende o interesse da manufatura e fábrica capitalistas incipientes antes os privilégio e monopólios das grandes companhias comerciais e coloniais, por outro lado, a indústria artesanal fechada em forma corporativa, por outro. Mas, a luta contra a ingerência do Estado só pôde ser levada a cabo quando se demonstrou que a legislação estatal era supérflua e prejudicial para a vida econômica. Ante as leis estatais, precisou-se demonstrar que a Economia se rege por leis próprias, sendo superior à legislação estatal.” (HILFERDING, 1985, 283).

${ }^{4}$ A burocracia administrativa é um instrumento de violência do Estado encarnada na figura déspota do administrador "que governa por relatórios e decretos, num sigilo pior que qualquer déspota oriental, surgiu de uma tradição de disciplina militar introduzida em meio a homens sem compaixão e leis. (...) E cumpriu essa tarefa de um modo ou de outro, enquanto vivia num mundo dominado pela velha 'trindade guerra, comércio e pirataria' (GOETHE) (...) Foi a burocracia a base organizacional do grande jogo da expansão, no qual cada zona era considerada um degrau para envolvimentos futuros, e cada povo era um Instrumento para futuras conquistas." (ARENDT, 1989, p. 216).

5 “(...) a burguesia alemã apostou tudo no movimento hitlerista para governar com o auxílio da escória, mas já era tarde demais para tal conquista do poder: a burguesia conseguiu destruir o Estado-nação que lhe perturbava o exercício da hegemonia, mas foi uma vitória de Pirro; a ralé mostrou-se perfeitamente capaz de cuidar da política por si mesma e liquidou a burguesia com todas as outras classes e instituições." (ARENDT, 1989, 154).

6 "Embora nunca inteiramente reconhecido, Hobbes foi o verdadeiro filósofo da burguesia, porque compreendeu que a aquisição da riqueza, concebida como processo sem fim, só pode ser garantida pela tomada do poder político, pois o processo de acumulação violará, mais cedo ou mais tarde, todos os limites territoriais existentes. Previu que uma sociedade que havia escolhido o caminho da aquisição contínua tinha de engendrar uma organização política dinâmica capaz de levar a um processo continuo de geração de poder" (ARENDT, 1989, p. 175) Podemos encontrar mesmo argumento numa outra
}

\begin{tabular}{|l|l|l|l|l|}
\hline Q Povista Qialectus & Ano 4 & n. 10 & Janeiro-Julho 2017 & p. 248-264 \\
\hline
\end{tabular}


Desta guerra de todos contra todos os homens também isto é consequência: que nada pode ser injusto. As noções de certo ou de errado, de justiça e injustiça, não podem aí ter lugar. Onde há poder comum não há lei, e onde não há lei não há injustiça. $\mathrm{Na}$ guerra, a força e a fraude são duas virtudes cardeais. A justiça e a injustiça não fazem parte das faculdades do corpo ou do espírito. Se assim fosse, poderiam existir num homem que estivesse sozinho no mundo, do mesmo modo que os sentidos e paixões. São qualidades que pertencem ao homem em sociedade, não na sociedade. Outra consequência da mesma condição é que não há propriedade, nem domínio, nem distinção entre o meu e o teu; só pertence a cada homem aquilo que ele é capaz de conseguir, e apenas enquanto for capaz de conservar. É, pois, nesta miserável condição que o homem realmente se encontra, por obra da simples natureza, embora com uma possibilidade de escapar a ela, que em parte reside nas paixões e em parte na sua razão (HOBBES, 2003, p. 111).

A proposta fundamental do realismo político, social e econômico de Hobbes na "acumulação do poder" é a capacidade de sustentar e conservar a sua condição natural no mundo diante da "guerra de todos contra todos", pois aqui "vale tudo" diante da condição miserável em que os homens vivem, isto é, não importa se algo é justo ou injusto, certo ou errado, mas se sou capaz de garantir "a minha vida em sociedade" e o "meu reconhecimento" de igualdade de natureza, que perante o outro é a condição de um ser capaz de matar o outro pela força ou pelo engenho que promove a condução da governabilidade e a instauração da "paz do soberano", (Cf. Idem, p. 123). Tal proposta

perspectiva no argumento de Hebert Marcuse ao salientar que "Hobbes, que pode ser chamado o mais característico filósofo da burguesia nascente, achara que sua filosofia política era compatível, primeiro, com a monarquia de Carlos I, depois, com o Estado revolucionário de Cromwell, e, finalmente, com a reação dos Stuart. Não importava para Hobbes, que o Estado soberano tomasse a forma de uma democracia, oligarquia ou monarquia limitada, contanto que afirmasse sua soberania nas relações com os outros Estados, e mantivesse sua autoridade em relação aos seus cidadãos. Assim, também para Hegel, não importavam as diferenças de forma política entre as nações, enquanto se mantivesse uniformemente a identidade subjacente ás relações sociais e econômicas que são as relações de sociedade da classe média" (MARCUSE, 2004, 153).

${ }^{7}$ É interessante notar o grau sarcástico sobre a ideia de paz promovida pelo soberano que está acima de tudo e de todos no pacto social pensado por Hobbes, nada mais é do que o soberano (tirano) ser tolerado odiosamente pela comunidade política (Cf. Idem, 174). Contudo, podemos verificar o contraponto proposto por Diderot ao argumentar de forma sarcástica nos verbetes políticos da Enciclopédia, intitulado - Direito Natural: "O que responderemos, então ao nosso raciocinador violento, antes de estrangulá-lo? Responderemos que todo o seu discurso se reduz a saber se ele adquire um direito sobre a existência dos outros ao entregar-lhes a sua, pois ele não quer apenas feliz, mas quer também ser justo, e pela sua equidade afastar para longe o epíteto de mau. Sem isto deveríamos sufocá-lo sem nada responder. Nós o faremos observar que, mesmo que aquilo que abandona lhe pertencesse tão completamente que pudesse dispor dele segundo seu desejo e mesmo que a condição que propõe aos outros lhe fosse vantajosa, isto não lhe daria nenhuma autoridade legítima que obrigasse os outros a aceitá-la; que aquele que diz 'quero viver' tem razão quanto o diz 'quero morrer'; que este só tem uma vida e que, ao abandoná-la, tornar se

\begin{tabular}{|l|l|l|l|l|}
\hline Q Povista Qialectus & Ano 4 & n. 10 & Janeiro-Julho 2017 & p. 248-264 \\
\hline
\end{tabular}


foi aceita pela "ralé e pelos seus líderes" como possibilidade do desenvolvimento e funcionamento eficaz do sistema capitalista que "precisava" de "novos pecados" para continuar o processo do "pecado original" do "acúmulo original de capital" (Cf. ARENDT, 1989, p. 185). E o acúmulo de capital mudou o conceito de "propriedade e riqueza" ao transformar o dinheiro num "negócio sacrossanto" que tornava as pessoas mais ricas não pela "aquisição e acúmulo" de propriedade, mas pelo processo interminável de consumo. E, a única forma de assegurar a posse do consumo é a sua destruição, "pois só possuímos para sempre e com certeza aquilo que destruímos" (Idem, p. 174).

O consumo foi "instrumentalizado" e a propriedade se sujeitou ao uso e ao cosumo $^{9}$ (Cf. Idem, p. 174) ou em termos modernos numa sociedade de consumidores que não percebe e não reconhece sua própria futilidade ${ }^{10}$ no processo de "acumulação contínua" que no mundo moderno não possibilita a distinção entre o bem público, o bem comum e os benefícios privados que se escamoteiam nos interesses próprios do homem sedento de poder, mas contraditoriamente transformado pela sociedade num pobre sujeitinho, sem direito e submetido ao tirano e a "Razão do Estado" do soberano que monopoliza e estraçalha os indivíduos ${ }^{11}$ ao torná-los "peça insignificantes na

senhor de uma infinidade de vidas; que se troca não seria justa mesmo se houvesse sobre a terra apenas ele e outro homem; que é absurdo exigir que outros queiram o que se deseja; que não é certo que o perigo ao qual expõe seu semelhante seja igual àquele ao qual quer se expor; que aquilo que ele arrisca pode não ser proporcional àquilo que o outro é forçado a arriscar; que a questão do direto natural é muito mais complicada do que pode parecer; que, no caso, ele é juiz e parte interessada, e que seu tribunal poderia muito bem não ser competente nesta questão." (DIDEROT, 2006, p. 80).

${ }^{8}$ Segundo Hannah Arendt, Marx “(...) percebeu de modo bastante consistente o pecado original do capitalismo na mudança do valor de uso para o valor de troca. No entanto, contra esses pecados de uma sociedade comercial, onde realmente o mercado de trocas é o lugar público, mas importante e onde, consequentemente, cada coisa se torna um valor intercambiável, uma mercadoria." (ARENDT, 2010, p. 206).

${ }^{9}$ Sobre esse assunto podemos argumentar com Hannah Arendt que chegamos próximos de "realizar o ideal do animal laborans" (Idem, p. 166) que "é o grau em que toda a nossa economia já se tornou uma economia de desperdício, na qual todas as coisas devem ser devoradas e descartadas quase tão rapidamente quanto apareceram no mundo, a fim de que o processo não chegue a um fim repentino e catastrófico. (Idem, ibidem, 166).

10 "Quanto mais fácil se torna a vida em sociedade de consumidores ou de trabalhadores, mais difícil será preservar a consciência das exigências das necessidades que a compele, mesmo quando a dor e o esforço, as manifestações externas das necessidades, são quase imperceptíveis. O perigo é que tal sociedade, deslumbrada pela abundância de sua crescente fertilidade e presa ao suave funcionamento de um processo interminável, já não seria capaz de reconhecer a sua própria futilidade - a futilidade de uma vida que "não se fixa nem se realiza em assunto algum que seja permanente, que continue a existir depois de terminando (seu) trabalho" (Idem, ibidem, p.167 - 168).

${ }^{11}$ Segundo Hannah Arendt - Thomas Hobbes “(...) previu como necessária a idolatria do poder que caracteriza esse novo tipo humano, e pressentiu que ele se sentiria lisonjeado ao ser chamado de animal sedento de poder, embora a sociedade o forçasse a renunciar a todas as suas forças naturais, suas virtudes e vícios, e fizesse dele o pobre sujeitinho que não tem sequer o direito de se erguer contra a tirana e que, longe de lutar pelo poder, submete-se a qualquer governo exigente e não mexe um dedo nem mesmo

\begin{tabular}{|l|l|l|l|l|}
\hline Q Povista Dialectus & Ano 4 & n. 10 & Janeiro-Julho 2017 & p. 24-264 \\
\hline
\end{tabular}


máquina de acumular poder" (Idem, 176), como se fosse uma máquina que devora o mundo e tudo aquilo que o constitui numa constante "guerra de todos contra todos" (HOBBES, 2003, p. 109) que é a igual capacidade de matar uns aos outros (Cf. Idem, p. 107) como uma lei natural da nossa condição humana "solitária, pobre, sórdida, embrutecida e curta" (Idem Ibidem, 109).

Como argumentou Thomas Hobbes: "Desta guerra de todos os homens contra todos os homens também é consequência: que nada pode ser injusto" (Idem, ibidem, 110). Neste sentido, não é demais citar Hobbes para entendermos as noções de pecado e crime na gênese do "Estado Moderno"12 e na figura do poder soberano na preservação do seu próprio corpo, pois:

Um crime é pecado que consiste em cometer (por atos ou palavras) algo que a lei proíbe, ou um omitir-se de algo que ela ordena. Assim, todos os crimes são pecados, mas nem todo pecado é um crime. A intenção de roubar ou matar é um pecado, mesmo que nunca se manifeste em palavras ou atos, por que Deus, que vê os pensamentos dos homens, pode culpá-lo. Mas antes de aparecer por meio de alguma coisa feita ou dita, em que um juiz humano possa descobrir a intenção, não se pode falar em crime. (...) Destas relações entre o pecado e a lei, entre o crime e a lei civil, pode inferir-se, em primeiro lugar, que quando acaba a lei acaba também o pecado. (...), onde acaba a lei civil acaba também o crime, pois na ausência de qualquer lei de natureza deixa de haver lugar para acusação, sendo cada homem seu próprio juiz, acusado apenas pela retidão da sua própria consciência e desculpado pela retidão das suas próprias intenções. (...), quando não há mais poder soberano também não há tal poder não é possível conseguir proteção da lei, e então cada um pode-se proteger com o seu próprio poder. Porque no momento da instituição do poder soberano não se pode supor que alguém renuncie o direito de preservar o seu corpo, para cuja segurança foi estabelecida a soberania. (HOBBES, 2003, p. $247-248)$.

quando o seu melhor amigo cai vítima de uma raison d'état incompreensível” (ARENDT, 1989, p. 175 176).

${ }^{12} \mathrm{Na}$ linha do que estamos refletindo e das questões internacionais entre a gênese dos Estados Modernos nós podemos recordar da reflexão críticas do Immanuel Wallerstein ao argumentar que o “(...) Estados mais forte têm mais capacidade de empreender ações contra Estados mais fracos que tentem limitar o efeito de monopólios situados em Estados Fortes, do que vice-versa. Os Estados mais Fortes podem operar diretamente (através da força política, econômica ou militar) ou por meio das estruturas do sistema inter-Estados (digamos, hoje, a Organização Mundial do Comércio). Assim, os produtores dos Estados mais fortes têm uma vantagem não mercadológica sob os produtores dos Estados mais fracos." (WALLERSTEIN, 2002, 11).

\begin{tabular}{|l|l|l|l|l|}
\hline Q Revista Qialectus & Ano 4 & n. 10 & Janeiro-Julho 2017 & p. 248-264 \\
\hline
\end{tabular}


Se a lei é feita por aqueles que possuem propriedades, podemos entender que eles (os proprietários) são aqueles que determinam as regras do jogo social, político e econômico nas sociedades modernas, pois estão no $\operatorname{poder}^{13}$ e precisam se manter no poder para proteger a si mesmos e as suas propriedades ${ }^{14}$, por "amor próprio" (fator racial), ${ }^{15}$ e lucro pelo lucro no acúmulo de poder. Com isso, podemos entender que não existe pecado ou crime na institucionalização da ação e repressão do soberano que age em benefício e em concordância com os interesses privados ${ }^{16}$ daqueles que o promoveram no poder do comando do Leviatã para preservar, legislar, cuidar e instaurar a paz da segurança soberana estabelecida.

O Leviatã de Hobbes expôs a única teoria política segundo a qual o Estado não se baseia em nenhum tipo de lei construtiva -

\footnotetext{
${ }^{13}$ Vale a pena verificar o entendimento sutil (não muito distante de Thomas Hobbes) de John Locke sobre a questão ao escrever no livro II dos Dois Tratados sobre o Governo: "Para evitar essa inconveniência que perturbam as propriedades dos homens no estado de natureza, eles se reúnem em sociedade, de modo que possam dispor da força reunida da sociedade como um todo para garantir e defender suas propriedades, e para disporem de regras fixas a delimitá-las e por cujo meio cada qual possa saber o que lhe pertence. É para esse fim que os homens renunciam a todo o seu poder natural em favor da sociedade em que ingressam, e a comunidade deposita o poder legislativo nas mãos que considera conveniente, confiando-lhe o encargo de que a sociedade seja governada por lei expressa. Do contrário, sua paz, tranquilidade e propriedade estarão entregues à mesma incerteza em que se encontravam no estado de natureza" (LOCKE, 2005, p. 507 - 508). John Locke em relação ao Thomas Hobbes subverte a "lógica do Soberano" que surge da reunião dos proprietários - proposta no Leviatã pela "lógica do Poder Legislativo" sacralizado nos homens que entram em sociedade pelo seu próprio consentimento. Contrário mesmo a posição destes dois senhores é J.J. Rousseau que argumentou que “(...) a origem da sociedade e das leis, que criaram novos entraves para o fraco e as novas forças para o rico, destruíram em definitivo a liberdade natural, fixaram para sempre a lei da propriedade e da desigualdade, de uma hábil usurpação fizeram um direito irrevogável e, para o lucro de alguns ambiciosos, sujeitaram daí para frente todo gênero humano ao trabalho, à servidão e à miséria" (ROUSSEAU, 2002, p. 212).

${ }^{14}$ Segundo J.-J. Rousseau "(...) o direito de propriedade não é mais que a convenção e instituição humana, qualquer homem pode dispor a seu bel-prazer daquilo que possui: mas não se dá a mesmo dons essenciais da natureza, tais como a vida e a liberdade, cujo gozo é permitido a todos e das quais é pelo menos duvidoso que se tenha o direito de despojar-se: privando-se de uma, degrada-se o próprio ser, privando-se da outra, aniquila-se tudo quanto existe em si próprio; e, como nenhum bem temporal pode compensar uma e outra, seria ofender a um só tempo a natureza e a razão renunciar a elas pelo preço que for" (ROUSSEAU, 2002, 230).

${ }^{15}$ Hannah Arendt ao argumentar sobre a "sobrevivência do mais apto" segundo a perspectiva dos nacionalistas dos ingleses destaca a figura do "amor-próprio" é uma chave de leitura do "gênio hereditário" descendente da seleção natural da raça pura da aristocracia que afirmava ser produto da natureza e não das convenções políticas, transferiu-se para a classe média e da classe média para o homem inglês superior, já que a Inglaterra é a história da sua evolução (Cf. ARENDT, 1989, 210). Contudo, "o aspecto mais perigoso dessas doutrinas evolucionista estava no fato de aliarem o conceito da hereditariedade à insistência nas realizações pessoais e nos traços de caráter individuais, tão importantes para o amor-próprio da classe média do século XIX. Essa classe média queria cientistas que provassem que os 'grandes homens' e não os aristocratas eram os verdadeiros representantes da nação em que se personificava o 'gênio da raça"” (Idem, p. 210 - 211).

${ }_{16}$ Conforme argumentou Jürgen Habermas existe uma tradição de pensadores liberais, como Locke, Quesnay, Adam Smith que defendem "o direito à propriedade como núcleo central do direito natural", pois "o interesse geral da sociedade deve poder ser satisfeito na livre concorrência entre os interesses individuais de proprietários privados" (HABERMAS, 2013, 171-172).
}

\begin{tabular}{|l|l|l|l|l|}
\hline Q Povista Qialectus & Ano 4 & n. 10 & Janeiro-Julho 2017 & p. 248-264 \\
\hline
\end{tabular}


seja divina, seja natural, seja contrato social - que determine o que é certo ou errado no interesse individual como relação às coisas públicas, mas sim nos próprios interesses individuais, de modo que o interesse privado e o interesse público são as mesmas coisas (ARENDT, 1989, p. 168 - 169).

Na visão da Hannah Arendt esse homem sem "moralidade" que vive em função dos seus interesses privados e que os fundem em benefícios públicos ao seu desejo e as suas razões de tudo acumular e ambicionar ao deter o poder para si mesmo é "uma função da sociedade”, que, “portanto, é julgado de acordo com o seu 'valor' ou merecimento (...) seu preço, ou seja, aquilo que se lhe daria pelo uso da força" (Idem, p. 168). Como argumenta Reinhart Kosellesck:

Sem autorização estatal, as leis da moral civil só existem, como em Hobbes, de maneira tácita e secreta, mas já não se restringem aos indivíduos enquanto tais: adquirem caráter obrigatório geral mediante o consentimento secreto e tácito dos cidadãos ('by $a$ secret and tacit consent'). $\mathrm{O}$ portado da moral secreta não é mais o indivíduo, mas a sociedade, a 'society' que se forma nos 'clubs', onde os filósofos se dedicam a investigar as leis morais. Os cidadãos não se submentem apenas ao poder estatal: juntos, formam uma sociedade que desenvolve suas próprias leis morais, que se situam ao lado das leis do Estado. Assim, a moral civil - ainda conforme a natureza, tacitamente e em segredo entra no espaço público. Além disto, pode-se perceber uma segunda modificação a que Locke submete a moral de convicção Hobbesiana: as leis morais civis, secretamente em vigor, não se restringem mais à convicção, mas determinam o valor moral das ações. Os próprios cidadãos estabelecem o que, em Hobbes, cabia exclusivamente ao soberano, isto é, a 'marca do valor' de todas as ações, se dão o nome de virtude às ações entre elas julgadas meritórias, e de vícios àquelas que consideram censuráveis (KOSELLECK, 1999, p.51).

Neste sentido, podemos argumentar que na perspectiva de Hobbes o homem torna-se refém do consentimento secreto ${ }^{17}$ das sociedades burguesa que tem o seu preço e o seu "valor" julgado pelo "dinheiro" da sociedade de acordo com a "lei de oferta e procura" como "valor moral" das suas ações, como argumentou Marx ao criticar essa postura de medida de valor e preço proposta por Hobbes, demonstrando que "o dinheiro

\footnotetext{
${ }^{17}$ Sobre esse assunto consultar o artigo da Hannah Arendt: A mentira na política: considerações sobre os documentos do Pentágono (ARENDT, 1999). E o artigo: Verdade e Política (ARENDT, 1992).
}

\begin{tabular}{|l|l|l|l|l|}
\hline Q Revista Qialectus & Ano 4 & n. 10 & Janeiro-Julho 2017 & p. 248-264 \\
\hline
\end{tabular}


é alcoviteiro entre a necessidade e o objeto, entre a vida e o meio de vida do homem. Mas o que medeia a minha vida para mim, medeia-me também a existência de outro homem para mim”. (MARX, 2005, p. 157).

Se o dinheiro é a medida de todas as coisas que medeia a "minha existência" e a "existência da vida dos outros homens", podemos considerar que o interesse, o desejo de poder, a vantagem na procura do preço e da oferta, as ambições, o conhecimento e a fama nada mais são do que a necessidade de "novo corpo político" da "burguesia em ascensão", que destrói toda a possibilidade de reciprocidades (Cf. MARX, 2004, p. 161) e até mesmo a ideia de segurança e confiança individual do pensamento liberal (Cf. LOCKE, 2005, 502), para fundamentar a sua crença no "processo interminável de acúmulo de propriedade" e no "infindável acumulo de poder" (ARENDT, 1989, 172) e do capital.

No que diz respeito ao processo da "acumulação do capital" como "pecado original do capital". Vejamos Marx:

(...) o capital, ao incorporar os dois formuladores originais da riqueza, a força de trabalho e a terra, adquire uma força expansiva que lhe permite estender os elementos de sua acumulação além dos limites aparentemente fixados por sua própria grandeza, limite estabelecidos pelo valor e pela massa dos meios de produção já produzidos, nos quais o capital tem sua existência. Outro fator importante na acumulação do capital é o grau de produtividade do trabalho social. Com a força produtiva do trabalho cresce a massa de produto na qual se representa um valor determinado e, portanto, também mais-valor de dada grandeza. Se a taxa de mais-valor se mantém constante, ou mesmo decrescente, sempre que ela diminui mais lentamente do que aumenta a força produtiva de trabalho, cresce a massa do mais-produto. Assim, mantendo-se inalterada a divisão do maisproduto em renda e capital adicional, o consumo do capitalista pode aumentar sem que diminua o fundo da acumulação. (MARX, 2013, p. 679).

Desse modo, podemos argumentar que o capital é incorporado pela atividade da produção da riqueza expropriada da força de trabalho (força corporal e consumida na energia laboral) e da terra alheia trabalhada "pelas nossas mãos" (ferramenta corporal na transformação da cultura e da "mundanidade" da nossa existência alienada ou interiorizada), dá existência (Dasein) ao capital metamorfoseado pelas relações produtivas do trabalho social, da divisão social do trabalho explorada, do mais-valor sujeitado ao processo da taxa de mais-valor que se transfigura na renda, no capital

\begin{tabular}{|l|l|l|l|l|}
\hline Q Rovista Dialectus & Ano 4 & n. 10 & Janeiro-Julho 2017 & p. 248-264 \\
\hline
\end{tabular}


adicional, no consumo do capitalista que aumenta o seu investimento produzido e acumulado sem diminuir o seu consumo. Sendo assim, podemos considerar o trabalho uma atividade vital do nosso corpo e não mera funcionalidade ${ }^{18}$, no processo progressivo do crescimento da riqueza expropriada do capitalista.

A grandeza proporcional desse fundo pode inclusive crescer à custo de consumo, enquanto o barateamento das mercadorias põe à disposição o capitalista uma quantidade igual ou maior de meios de satisfação do que antes. Porém a produtividade crescente do trabalho acompanha, como vimos, o barateamento do trabalhador e, portanto, uma taxa de mais-valor, mesmo quando o salário real aumenta. Este nunca aumenta na mesma proporção da produtividade do trabalho. Portanto, o mesmo valor de capital variável põe em movimento mais força de trabalho e, por conseguinte, também mais trabalho. O mesmo valor de capital constante se representa em mais meios de produção, isto é, mais meios de trabalho, material de trabalho e matérias auxiliares, fornecendo, assim, tanto mais formadores de produto como mais formadores de valor, ou absorvedores de trabalho. Se o valor do capital adicional se mantém constante, ou mesmo decrescente, ocorre, pois, uma acumulação acelerada. Não apenas se amplia materialmente a escala da reprodução, mas a produção do mais-valor cresce mais rapidamente que o valor do capital original. (Idem, p. 679- 680).

O consumo é uma atividade privativa ao corpo do trabalhador que se metamorfoseia em atividade de trabalho e consumo metabólico do corpo que consome e é consumido pela atividade de trabalho, pois o corpo foi transformado na única propriedade do trabalhador que vende a sua força de trabalho e se desapropria e alienase do seu corpo na medida em que o vende pela medida do "valor dinheiro" que foi valorado no salário real da "sociedade de trabalho ou assalariado" (ARENDT, 2010, 143) que o transforma numa mercadoria determinada pelos meios e processos de produção da própria "vida objetivada" em materialidade (em produto) que deixa de ser propriedade e se transforma num processo acelerado de "acumulação e crescimento da riqueza" na produção do mais-valor que acelera em velocidade infinita a valoração do

\footnotetext{
${ }^{18}$ Como argumentou Jürgen Habermas em Conhecimento e Interesse: “(...) o trabalho não é apenas uma categoria antropologicamente fundamental, é ao mesmo tempo uma categoria ligada à teoria do conhecimento. O sistema das atividades objetivas cria as condições factuais da reprodução possível da vida social e, ao mesmo tempo, as condições transcendentais da objetividade possível dos objetos da experiência. Se nós concebemos o homem sob a categoria de um animal fabricante de instrumentos, visamos, com isso, um esquema de ação e de concepções de mundo de uma só vez. O trabalho é na qualidade de processo natural, mais do que um mero processo natural, ele regula o metabolismo e constitui o mundo." (HABERMAS, 2014, p.60 - 61).
}

\begin{tabular}{|l|l|l|l|l|}
\hline Q Ponita Qialectus & Ano 4 & n. 10 & Janeiro-Julho 2017 & p. 248-264 \\
\hline
\end{tabular}


capital original desenfreados das "forças produtivas das sociedades" automatizadas no "processo vital do trabalho" consumido pela violência do capital que "consume os seus serviços" (Cf. Idem, p. 151) ${ }^{19}$ que amplia a celebração da orgia (Cf. MARX, 2013, p. 350) a proporcionalidade vampiresca (Cf. Idem, 307) de sugar o sangue do trabalhador individualizado no "trabalho comum" e socializado da "força de trabalho" de um único "corpo coletivo" no "progresso da acumulação de riqueza ilimitada" da "humanidade socializada" dilacerada na "divisão do trabalho" e "na mecanização da sua atividade" produtiva em massa, que substitui a especialização artesanal (Cf. ARENDT, 2010 p. 154). Como argumentou Marx:

Os meios de produção converteram-se imediatamente em meio para a sucção de trabalho alheio. Não é mais o trabalhador que emprega os meios de produção, mais os meios de produção que emprega o trabalhador. Em vez de serem consumidos por ele como elementos materiais de sua atividade produtiva, são eles que consomem como fermento de seu próprio processo vital, e o processo vital do capital não é mais do que seu movimento como valor que valoriza a si mesmo (MARX, 2013, 382).

Com isso, podemos argumentar que a "divisão do trabalho" instrumentalizou a "massificação do trabalho" e transformou o trabalhador num escravo das necessidades de consumo e do ciclo vital interminável produção impostas pela necessidade da vida sacrificada no "produto do trabalho" abundante e interminável da "sociedade dos consumidores" que aumenta o poder e o valor do capital original violentamente no "uso dos objetos" transfigurados em "objetos de consumo" e de "bens de consumo" em algo insignificante (Cf. ARENDT, 2010 p. 155 - 156), ${ }^{20}$ isto é supérfluo como o trabalho e o

\footnotetext{
${ }^{19} \mathrm{Na}$ perspectiva do István Mészáros podemos entender “(...) que o sistema do capital - como se dá com todas as formas concebíveis de controle sociometabólico global, inclusive a socialista - está sujeito à lei absoluta do desenvolvimento desigual, que sob a regra do capital, vigora numa forma em última análise destrutiva, por causa de seu princípio estruturador interno antagônico. Assim, para prever uma resolução global, legítima e sustentável dos antagonismos do sistema do capital, seria necessário primeiro acreditar no conto de fadas da eliminação para todo o sempre da lei do desenvolvimento desigual das questões humanas. É por isso que a 'Nova Ordem Mundial' é uma fantasia absurda ou uma camuflagem cínica planejada para projetar os interesses hegemônicos dos poderes capitalistas preponderantes como aspiração universalmente benéfica e moralmente recomendável da espécie humana." (MÉSZAROS, 2002, p. 114).

${ }^{20}$ Sobre esse assunto vale a pena verificar o argumento do Immanuel Wallerstein: "As consequências a médio prazo também são claras. Haverá um grupo estaticamente significante de família migrantes (incluindo frequentemente famílias de segunda geração) mal renumeradas, não integradas socialmente, e quase certamente sem direitos políticos. Essas pessoas constituirão essencialmente o estrato mais baixo da classe trabalhadora em cada país. Se este for realmente o caso, estaremos de volta à situação pré-1848 na Europa ocidental - uma subclasse concentrada nas áreas urbanas, sem direitos políticos e portadoras de queixas muito robustas, e desta vez claramente identificáveis do ponto de vista étnico. Foi uma situação
}

\begin{tabular}{|l|l|l|l|l|}
\hline Q Ponita Qialectus & Ano 4 & n. 10 & Janeiro-Julho 2017 & p. 248-264 \\
\hline
\end{tabular}


homem que não é "capaz de reconhecer a sua própria futilidade - a futilidade de uma vida que 'não se fixa nem se realiza em assunto algum que seja permanente, que continue a existir depois de terminado (seu) trabalho" (Idem, p. 168). É significativo o argumento do István Mészaros sobre o assunto, mesmo que a partir de outro ponto de vista filosófico:

A expansão desenfreada do capital desses últimos anos séculos abriu-se não apenas em respostas a necessidades reais, mas também por gerar apetites imaginários e artificiais - para os quais, em princípio, não há limite, a não ser a quebra do motor que continua a gerá-lo em escala cada vez maior e cada vez mais destrutiva - pelo modo de existência independente e pelo poder de consumo auto-afirmativo. $\mathrm{Na}$ verdade, prevalece a necessidade ideológica da ordem estabelecida, produzindo racionalizações complicadas que visam esconder as profundas iniquidades das relações estruturais dadas também na esfera do consumo. Tudo deve ser desvirtuado para proporcionar a impressão de coesão e unidade, projetando a imagem de uma ordem saudável e racionalmente administrável. Para isso, as relações sociais descritas por Hobbes como 'bellum omnium contra omnes' - com sua tendência objetiva a deixar os fracos serem devoradas pelos fortes - é idealizada como 'competição saudável' universalmente benéfica. A serviço dos mesmos objetivos, as condições reais pelas quais a esmagadora maioria da sociedade é excluída, de forma estruturalmente prejulgada e legalmente protegida, da possibilidade de controlar o processo socioeconômico de reprodução - inclusive, naturalmente, os critérios de regulação e do consumo - são ficcionalizados como soberania do consumidor individual. (MÉSZAROS, 2002, p. 109).

A tragédia instaurada pela relação entre o processo de acumulação original do capital, a força de trabalho social, o consumo e o acúmulo de riqueza ilimitada do capitalista acelerada pelo capital original pode eliminar a sociedade produtora e gerar um "capital supérfluo", dinheiro supérfluo e homens supérfluos, que juntos, estabeleceriam "o primeiro paraíso de parasita, cujo o sangue vital era o outro" (ARENDT, 1989, p. 181) saudavelmente administrado para obtenção da falsa ordem do "sistema mundial totalitário" 21 dos donos do capital. Na analise da Hannah Arendt:

deste tipo que levou ao primeiro espectro de que falaram Marx e Engels." (WALLERSTEIN, 2002, p. 49).

${ }^{21}$ Entendemos o sistema mundial totalitário como o "(...) domínio totalitário, como a tirania, traz em si o germe da sua própria destruição. Tal como o medo e a impotência que vem do medo são princípios antipolíticos e levam os homens a uma situação contrária à ação política, também a solidão e a dedução

\begin{tabular}{|l|l|l|l|l|}
\hline Q Povista Qialectus & Ano 4 & n. 10 & Janeiro-Julho 2017 & p. 248-264 \\
\hline
\end{tabular}


Os donos do capital supérfluo foram o primeiro segmento dessa classe a desejar lucros sem exercer qualquer função social verdadeira - mesmo que se tratasse da função de um produtor que explorasse os outros - e, consequentemente, nenhuma polícia poderia jamais tê-los salvo da ira do povo. A expansão, portanto, não foi apenas uma fuga para o capital supérfluo. $\mathrm{O}$ mais importante é que protegia os seus donos contra a ameaçadora perspectiva de permanecerem inteiramente supérfluo e parasitário. Salvou a burguesia das consequências dá ma distribuição e revitalizou o seu conceito de propriedade numa época em que a riqueza já não podia ser usada como fator produtivo dentro do âmbito nacional, entrando em conflito com o ideal de produção vista como um todo (ARENDT, 1989 p. 181).

Com isso, podemos sugerir pela leitura da Hannah Arendt que o “(...) imperialismo, produto de dinheiro supérfluo e de gente supérflua, iniciou sua surpreendente carreira produzindo bens dos mais supérfluos e irreais" (Idem, p. 181), mas como estrutura e expressão de violência, agressividade e luta no processo da acumulação política do capital exportado ${ }^{22}$, como entendeu Rosa Luxemburgo ao argumentar que:

(...) o capitalismo considera, como uma questão vital, a apropriação violenta dos meios de produção mais importantes dos países coloniais. Como os laços tradicionais dos indígenas constituem a muralha mais forte de sua organização social e a base de suas condições materiais de existência, o método inicial do capital é a destruição e o aniquilamento sistemático das estruturas sociais não capitalistas, com que tropeça em sua expansão. Isso não significa já a própria acumulação primitiva, mas seu processo continua até hoje. Cada nova expansão colonial é acompanhada, naturalmente, dessa luta encarniçada do capital contra a situação econômica dos indígenas que compreende a apropriação violenta de seus meios de produção e de sua força de trabalho. (...) O capital só conhece, como solução para esse problema, o uso da violência, que constitui um método permanente da acumulação de capital no processo

do pior por meio da lógica ideológica, que advém da solidão, representam uma situação anti-social e contêm um princípio que pode destruir toda forma de vida humana em comum. Não obstante, a solidão organizada é consideravelmente mais perigosa que a impotência organizada de todos os que são dominados pela vontade tirânica e arbitrária de um só homem. É o seu perigo que ameaça devastar o mundo que conhecemos - um mundo que, em toda parte, parece ter chegado ao fim - antes que um novo começo, surgindo desse fim, tenha tido tempo de firmar-se." (ARENDT, 1989, 530).

22 "É por isso que o relacionamento entre o Estado e as empresas economicamente relevantes neste campo é basicamente caracterizado pelo fato de o Estado assumir descaradamente o papel de facilitador da expansão mais monopolista possível do capital no exterior" (MÉSZAROS, 2002, p. 113).

\begin{tabular}{|l|l|l|l|l|}
\hline Q Povista Qialectus & Ano 4 & n. 10 & Janeiro-Julho 2017 & p. 248-264 \\
\hline
\end{tabular}


histórico, desde sua origem até os nossos dias (LUXEMBURGO, 1970, p. 319 - 320).

O fenômeno imperialista produz e exporta o "capital e gente supérflua", sem nenhum compromisso com a "força social organizada" do povo colonizado, pois instrumentalizam seus ataques, assaltos e métodos a "população autônoma", com o braço estendido do Estado que se perpetua no monopólio da "força e da violência militar" que desapropria e priva toda forma de "vida organizada e socialmente produtiva" das populações colonizadas em nome da expansão e da acumulação do capital que gera a exploração, a dominação e desejo do lucro a qualquer preço da sociedade administrada pela ascensão da ralé no poder.

A expressão do fenômeno imperialista, com isso, desvela e faz notar a singularidade da ralé que foi "gerada pela monstruosidade da acumulação" e do "capital supérfluo" (cf. Idem, 181), ou seja, como "subproduto da sociedade burguesa, gerado por ela diretamente, portanto, nunca separada dela completamente” (Idem, p. 185), no processo administrativo do corpo político do Estado moderno ${ }^{23}$. Como Hannah Arendt argumentou:

O surgimento da ralé na organização capitalista foi observado desde cedo, e o seu crescimento foi notado por todos os grandes historiadores do século XIX. O pessimismo histórico, de Burckhardt a Spengler, deve-se essencialmente a essa observação. Mas o que os historiadores, tristemente preocupados com o fenômeno em si deixaram de perceber é que a ralé não podia ser identificada com o crescimento da classe trabalhadora industrial, e certamente não com o povo como um todo, composta que era do refugo de todas as classes. Essa composição fazia parecer que a ralé e seus representantes haviam abolido as diferenças de classe e que aqueles que se haviam alienado da nação dividida em classes era o próprio povo (a Volksgemeinschaft, como a chamaria os nazistas) e não sua distorção e caricatura (Idem, p 185).

\footnotetext{
${ }^{23}$ Podemos lembrar mais vez que a “(...) formação do Estado moderno é uma exigência absoluta para assegurar e proteger permanentemente a produtividade do sistema. O Capital chegou à dominância no reino da produção material paralelamente ao desenvolvimento das práticas totalizadoras que dão forma ao Estado Moderno." (Idem, p. 106). A partir do registro de Max Weber o empreendimento estatal é o domínio da administração e do funcionário na direção política, pois "em um Estado moderno, o domínio efetivo, que não se manifesta nos discursos parlamentares nem em declarações de monarcas, mas sim no cotidiano da administração, encontra-se, necessária e inevitavelmente, nas mãos do funcionalismo, tanto militar quanto civil, pois também o oficial superior moderno dirige as batalhas a partir do "escritório" (WEBER, 2009, p.529)
}

\begin{tabular}{|c|c|c|c|c|}
\hline Q Ponista Dialectus & Ano 4 & n. 10 & Janeiro - Julho 2017 & p. $248-264$ \\
\hline
\end{tabular}


Acompanhando o pensamento da Hannah Arendt podemos perceber que a questão chave para o entendimento da ralé é a composição do refugo de todas as classes e "subproduto da burguesia" 24 destituída de princípios e com um gosto apurado para o cinismo anárquico e a criminalidade do submundo e do vício, e não o povo como um todo ou uma classe trabalhadora apartada do "povo comum" como sugeriram os nazistas e até deixaram de perceber os historiadores pessimistas ${ }^{25}$. Contudo, os historiadores pessimistas entenderam que o que a "democracia" poderia se transformar num “despotismo", no qual o tirano poderia aparecer com o apoio da ralé. (Cf. Idem, p. 185).

Esse novo tipo de homem como traço característico da ralé, isto é, da composição do refugo de todas as classes e do subproduto da burguesia e que nunca se separa dela, faz recordar na visão da Hannah Arendt da concepção de homem desenhada por Hobbes no Leviatã que possui capacidade de igualdade como os outros homens de matar uns aos outros.

\section{Considerações finais:}

Devemos destacar que esse novo homem da ralé vai formar a "classe dos burocratas" do Estado-nação, com "status senhores" destruidores dos povos dominados com poderes de empregar e administrar a violência como política de "força do Estado"26 que é capaz de influenciar o corpo político e a estrutura política da sociedade pela "força das nações" expansionistas como uma nova classe em nome do "Estado moderno imperialista"27 que aplica a sua força, os seus instrumentos de violência e o seus recursos policiais como possibilidades de alavancar a superprodução do capital, o surgimento do dinheiro supérfluo e a expansão totalitária destruidora dos povos e

\footnotetext{
24 "E Malthus, que posteriormente desenvolveu aquela afirmação de Smith, a seu modo tem razão ao sustentar que sempre há população supérflua, indivíduos demais no mundo - apenas equivocou-se de todo ao sustentar que há mais indivíduos do que aqueles que os meios de subsistência existentes podem alimentar. A população supérflua é produto da concorrência entre os trabalhadores, que obriga cada trabalhador a laborar cotidianamente até o limite de suas forças.” (ENGELS, 2010 p. 122).

25 “A atração que o mal e o crime exerceram sobre a mentalidade da ralé não é novidade. Para a ralé, os 'atos de violência podiam ser perversos, mas eram sinal de esperteza'. Mas o que é desconcertante no sucesso do totalitarismo é o verdadeiro altruísmo dos seus adeptos.” (ARENDT, 1989, p. 357).

26 “(...) a estrutura legal do Estado moderno é uma exigência absoluta para o exercício da tirania nos locais de trabalho. Isso se deve à capacidade do Estado de sancionar e proteger o material alienado e os meios de produção (ou seja, a propriedade radicalmente separada dos produtores) e suas personificações, os controladores individuais (rigidamente comandados pelo capital) dos processos de reprodução econômicas." (MÉSZAROS, 2002, p. 107).

${ }^{27}$ Para Hegel o Estado é o todo que decide entre a paz, guerra e expansão, pois o "Se todo assim levanta em poder e arranca à vida interior para voltar para o exterior, então a guerra de defesa transforma-se numa guerra de conquista.” (HEGEL, 2003, 299 ou § 326).
}

\begin{tabular}{|l|l|l|l|l|}
\hline Q Povista Dialectus & Ano 4 & n. 10 & Janeiro-Julho 2017 & p. 248-264 \\
\hline
\end{tabular}


nações $^{28}$ (Idem, p. 167) pelas expressões ideológicas racistas, pela substituição da ideia de nação pela unidade racial, pelas ilusões "progressistas" com características imperialistas no mundo fantasma do continente negro e do imperialismo continental da ilegalidade que "parece ser legal" na burocracia do governo que imprime leis por decretos e transforma a "lei" numa força constitucional direta administrada pelos peritos e especialistas do Estado que expurgam a espontaneidade popular das ações em conjunto das atividades políticas do corpo social do Estado, pois a ideia fundamental do imperialismo é continuar expandindo "o Capital supérfluo" para o sistema não parar e imprimir todo o processo imperial que se estrutura com a exploração, a ciência para a seleção dos "melhores" e a tecnologia desenvolvida para dar suporte ao assalto e a expropriação da propriedade alheia na guerra de "todos contra todos" que impulsiona praticas predatórias, militares, raciais e imperialistas das altas finanças ditadas pelas altas taxas de lucros como direitos inalienáveis e sagrados para os donos do capital supérfluos.

\section{Referências bibliográficas:}

ARENDT, Hannah. Origens do totalitarismo. Tradução Roberto Raposo. São Paulo: Companhia das Letras, 1989.

ARENDT, Hannah. Entre o passado e o futuro. Tradução de Mauro W. Barbosa de Almeida. São Paulo: Editora Perspectiva, 1992.

ARENDT, Hannah. Crise da república. Tradução de José Volkmann. S São Paulo: Editora Perspectiva, 1999.

ARENDT, Hannah. A condição humana. Tradução Roberto Raposo. São Paulo: Rio de Janeiro: Forense Universitário, 2010.

DIDEROT, Denis. Verbetes políticos da enciclopédia. Tradução de Maria das Graças de Souza. São Paulo: Discurso Editorial: Editora Unesp, 2006.

ENGELS, Friedrich. A situação da classe trabalhadora na Inglaterra. Tradução B. A. Schumann. São Paulo: Boitempo, 2010.

HABERMAS, Jürgen. Conhecimento e interesse. Tradução Luiz Repa. São Paulo: Editora Unesp, 2014.

\footnotetext{
28 "No sistema do capital, o Estado deve afirmar, com todos os recursos à sua disposição, os interesses monopolistas de seu capital nacional - se preciso, com a imposição da 'diplomacia das canhoneiras' diante de todos os Estados rivais envolvidos na competição pelos mercados necessários à expansão e à acumulação do capital" (MÉSZAROS, 2002, p. 113).
}

\begin{tabular}{|l|l|l|l|l|}
\hline Q Povista Dialectus & Ano 4 & n. 10 & Janeiro-Julho 2017 & p. 248-264 \\
\hline
\end{tabular}


HEGEL, Georg Wilhelm Friedrich. Princípios filosofia do direito. Tradução Orlando Vitorino. São Paulo: Martins Fontes, 2003.

HILFERDING, Rudolf. O capital financeiro. Tradução Reinaldo Mestrinel. São Paulo: Nova Cultural, 1985.

HOBBES, Thomas. Leviatã ou matéria, forma e poder de um Estado Eclesiástico e Civil. Tradução João Paulo Monteiro e Maria Beatriz Nizza da Silva. São Paulo: Nova Cultural, 2003.

KOSELLECK, Reinhart. Crítica e crise. Tradução de Luciana Villas-Boas CasteloBranco. Rio de Janeiro: EDUERJ: Contraponto, 1999.

LOCKE, John. Dois tratados sobre o governo. Tradução Julio Fischer. São Paulo: Martins Fontes, 2005.

LUXEMBURGO, Rosa. A acumulação do capital: estudos sobre a interpretação econômica do imperialismo. Tradução Moniz Bandeira, Rio de Janeiro: Zahar Ediotres, 1970.

MARX, Karl. Manuscritos econômico-filosóficos. Tradução Jesus Ranieri. São Paulo: Boitempo, 2004.

MARX, Karl. O capital: critica da economia política: livro I: o processo de produção do capital. Tradução Rubens Enderle. São Paulo: Boitempo, 2013.

MÉSZAROS, István. Para além do Capital: rumo a uma teoria da transição. Tradução Paulo César Castanheira e Sérgio Lessa. São Paulo: Boitempo: Campinas, SP: Editora Unicamp, 2002.

ROUSSEAU, Jean-Jacques. Discurso sobre a origem e os fundamentos das desigualdades entre os homens. Tradução Maria Ermantina Galvão. São Paulo: Martins Fontes, 2002.

WALLERSTEIN, Immanuel. O fïm do mundo como o concebemos: ciência social para o século XXI. Tradução Renato Aguiar. Rio de Janeiro: Revan, 2002.

WEBER, Max. Economia e sociedade: fundamentos da sociologia compreensiva. Tradução Regis Barbosa e Karen Elsabe Barbosa. Brasília: Editora Universidade de Brasília, 1999, 2009 (reimpressão).

\begin{tabular}{|l|l|l|l|l|}
\hline Q Ronista Dialectus & Ano 4 & n. 10 & Janeiro - Julho 2017 & p. 248-264 \\
\hline
\end{tabular}

